\title{
Functional fatigue of NiTi Shape Memory wires for a range of end loadings and constraints
}

\author{
G. Scirè Mammano, E. Dragoni \\ Department of Engineering Sciences and Methods, University of Modena and Reggio Emilia - Reggio Emilia - Italy \\ giovanni.sciremammano@unimore.it
}

\begin{abstract}
The availability of engineering strength data on shape memory alloys (SMAs) under cyclic thermal activation (functional fatigue) is central to the rational design of smart actuators based on these materials. Test results on SMAs under functional fatigue are scarce in the technical literature and the few data available are mainly limited to constant-stress loading. Since the SMA elements used within actuators are normally biased by elastic springs or by another SMA element, their stress state is far from constant in operation. The mismatch between actual working conditions and laboratory arrangements leads to suboptimal designs and undermines the prediction of the actuator lifetime. This paper aims at bridging the gap between experiment and reality. Four test procedures are planned, covering most of the typical situations occurring in practice: constant-stress, constant-strain, constant-stress with limited maximum strain and linear stress-strain variation with limited maximum strain. The paper describes the experimental apparatus specifically designed to implement the four loading conditions and presents fatigue results obtained from commercial NiTi wires tested under all those protocols.
\end{abstract}

KEYWORDS. SMA wires; Functional fatigue; Constant-stress; Constant-strain; Limited maximum strain; Linear stress-strain variation.

\section{INTRODUCTION}

S hape memory alloys (SMAs) are increasingly employed to build solid state actuators, characterized by sleek design and outstanding power density. For the rational design of shape memory actuators, a thorough knowledge of the fatigue behaviour of the alloy is needed [1]. Since the actuation is always provided by thermal activation of the alloy, the fatigue incurred by the material is called "thermomechanical" or "functional", implying that material performs mechanical work against the external applied load when heated during the actuation cycle.

Although the purely mechanical fatigue (i.e. at constant temperature) of shape memory alloys is well established in the technical literature [2], only scanty data exist on the response of these materials to functional fatigue. Furthermore, the few papers available on functional fatigue of shape memory alloys are limited to the constant-stress loading condition and cover a very limited number of cycles [3-5].

Test methods different from the constant-stress concept were carried out in [6] and [7]. Mertmann et al. [6] investigated the stability of the shape memory effect under constant-strain conditions. They observe that memory effect is quickly lost under these conditions accompanied by a general elongation of the specimen. Demers et al. [7] tested the functional fatigue of a NiTi alloy after various thermomechanical training processes based on three steps: "stress-free shape recovery", "constrained recovery" (constant-strain) and "constant-stress recovery" (assisted-two-way-shape-memoryeffect).

The authors have lately started a systematic test campaign on SMA wires undergoing realistic functional fatigue cycles [8, 9]. A specific testing machine has been designed and built to implement a variety of loading conditions likely to be 
encountered in practice. Test results have been published for three arrangements: constant-stress, constant-strain and constant-stress cycle with limited maximum strain $[8,9]$. This paper reviews those results and presents a new experimental set-up to test SMA wires under a linear variation of stress and strain. Preliminary experimental data obtained under this loading condition are also presented and discussed in comparison with the outcomes of the previous tests.

\section{MATERIALS AND METHODS}

\section{Characteristic stress-strain tests}

7 ypically, a shape memory actuator comprises an active SMA element (for example a wire) and a backup element (for example a spring) used to restore the reference position when the SMA element is deactivated. The particular load acting on the active element strongly depends on the backup element and on the external load applied to the actuator.

Fig. 1 illustrates four test conditions in which the stress and the strain in the SMA element vary along specific paths representative of what can occur in operation.

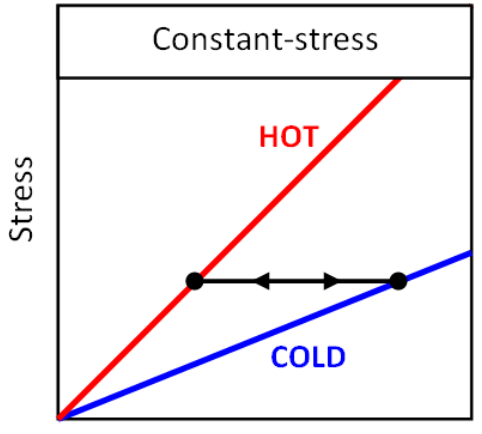

Strain

(a)

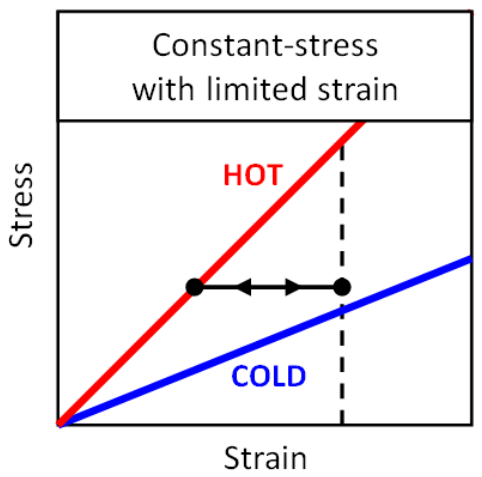

(c)

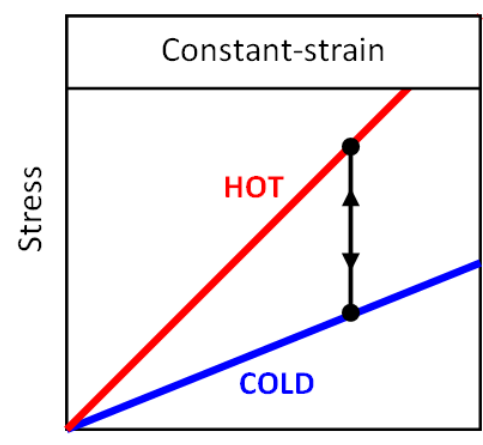

Strain

(b)

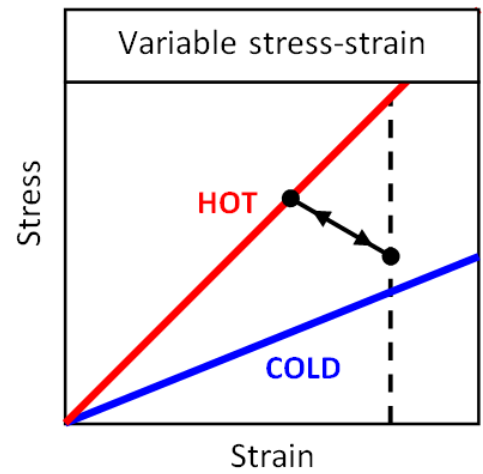

(d)

Figure 1: Specific tests proposed to characterize the SMA wires under functional fatigue: a) constant-stress; b) constant-strain; c) constant-stress with limited maximum strain; d) linear stress-strain cycle.

Fig. 1a describes the classical constant-stress test, in which the SMA element undergoes variable strain under prescribed stress, provided for example by an applied constant load. This test reproduces the situation occurring in an actuator backed up by a constant force and operated under no external load (positioning device). Given the material, this test is fully defined by the stress applied to the SMA element.

Fig. 1b describes the constant-strain test, in which the SMA element undergoes variable stress under prescribed strain, provided for example by rigid restraints fixing the ends of the sample. This test reproduces the situation in which the actuator is operated in a locked position. Given the material, this test is fully defined by the strain imposed to the SMA element.

Fig. 1c describes a constant-stress test with limited maximum strain, in which the SMA element undergoes variable strain under prescribed stress but the maximum strain achievable is limited by an external restraint. This test reproduces the 
situation in which an actuator backed up by a constant force works between hard stops. Given the material, this test is fully defined by two parameters: the applied stress and the maximum strain.

Fig. 1d describes a cyclic-stress test, in which the SMA element undergoes a linear variation of stress and strain, with the stress level increasing during strain recovery and the maximum strain limited by an external restraint. This test reproduces the situation in which the SMA element of an actuator is backed up by a spring (or another SMA element) and works between hard stops. Given the material, this test is defined by three parameters: the stress-strain slope, the maximum strain, the initial stress at the maximum strain.

\section{Properties of the tested shape memory alloy}

To the aim of gathering fatigue data on shape memory materials readily available to the designer, the NiTi wire Smartflex ${ }^{\circledR} 150$ marketed by SAES Getters was used throughout the experimental campaign. The wire has a diameter of $0.150 \mathrm{~mm}$, a $\mathrm{Ni}$ content of $54 \%$ by weight and the following transformation temperatures: $\mathrm{A}_{\mathrm{s}}=86^{\circ} \mathrm{C}, \mathrm{A}_{\mathrm{f}}=94^{\circ} \mathrm{C}$, $\mathrm{M}_{\mathrm{s}}=65^{\circ} \mathrm{C}, \mathrm{M}_{\mathrm{f}}=57^{\circ} \mathrm{C}$. The stress-strain tensile properties of the wire in the martensitic and austenitic states are presented in [8].

\section{Experimental equipment}

The custom test machine used to apply the stress-strain conditions of Fig. 1 is described in detail in [8]. Basically, the machine comprises a C-shaped aluminium chassis to which a secondary plastic frame is attached. The upper part of the plastic frame holds the primary load cell to which one end of the SMA wire under test is attached through a rigid clamp. The lower end of the SMA wire is loaded or constrained as shown in Fig. 2, according to the test to be performed. Heating of the wire is provided by electric current supplied by an electronic power board. A fan maintains a constant air flow across the wire [8] with the double purpose of reducing the cycle time during cooling (electric power switched off) and improving the uniformity of the temperature along the wire during heating. Although the temperature was not measured directly during the tests, a numerical simulation (not reported here) has shown that under the adopted conditions of forced convection the temperature is fairly constant over the wire length. The only regions of significant temperature deviation are the short portions of the wire close to the end crimps in contact with the cooler frame [9].

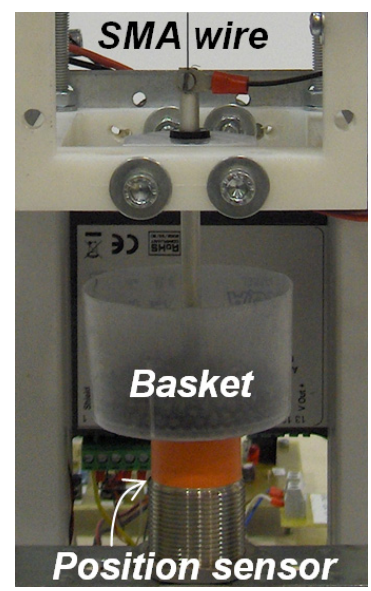

(a)

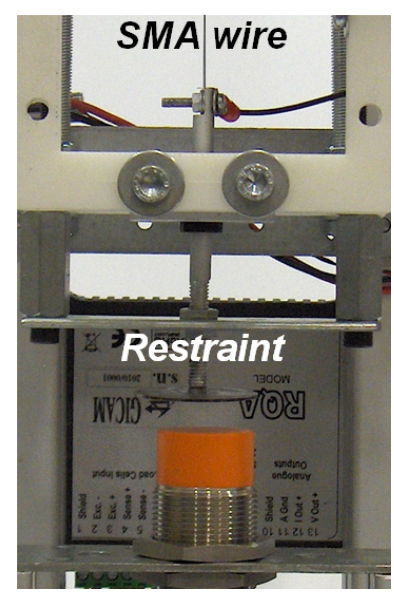

(b)

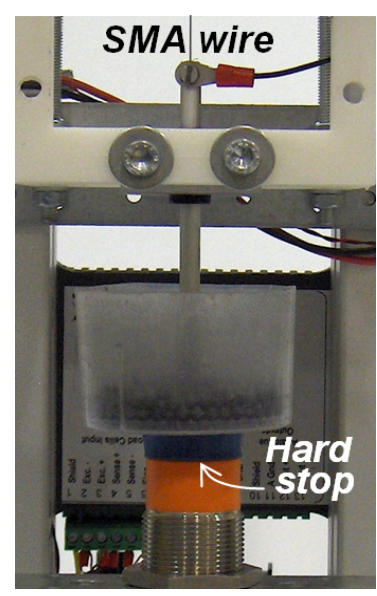

(c)

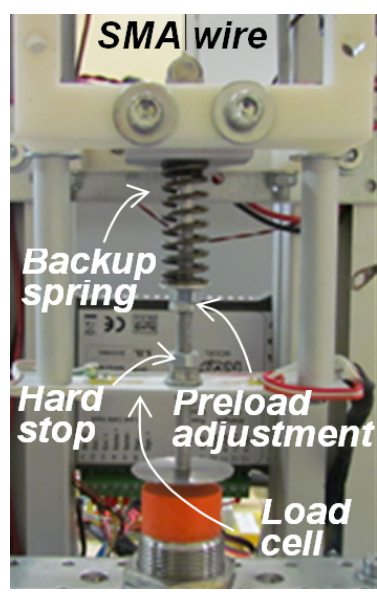

(d)

Figure 2: Details of the apparatus used to apply the four test conditions of Fig. 1: (a) constant-stress; (b) constant-strain; (c) constantstress with limited maximum strain; (d) linear stress-strain cycle.

The supplied current and the signals from the sensors (load cell and displacement transducer) are picked up, processed and controlled by a DAQ board (National Instruments USB 6251). The operating parameters are displayed on the graphical user interface developed in LabView ${ }^{\circledR}$, and the sensors signals are stored continuously on disk.

In the configuration detailed in Fig. 2a, with a loading basked appended to the wire, the machine performs the constantstress test of Fig. 1a. By removing the basket and locking the bottom end of the rod as in Fig. 2b, the constant-strain test condition of Fig. $1 \mathrm{~b}$ is achieved. By placing a polymer spacer on top of the displacement sensor to function as a hard stop for the loading basket (Fig. 2c), the test condition in Fig. 1c (constant-stress with limited maximum strain) is performed. The implementation of the test condition "linear stress-strain cycle" (Fig. 1d) is shown in Fig. 2d. A traditional compression spring, mounted between the frame and an adjusting nut on the sliding rod, provides the backup force on 
the wire according to a linear stress-strain variation. The spring rate of the spring controls the slope of the stress-strain path. The equipment accepts springs with internal diameters from $6 \mathrm{~mm}$ and free lengths up to $60 \mathrm{~mm}$. The limit maximum strain is adjustable by a flange nut which functions as a hard stop for the rod. Another nut provides the desired preload of the spring. The exact preload of the spring is verified by the instrumented aluminum plate, which functions as secondary load cell.

It should be noted that in the constant stress test with limited strain and in the linear stress-strain cycle, the stress is strictly constant and, respectively, linearly variable only as long as the moving end of the wire is not in contact with the bottom restraint (hard stop) used to limit the strain. When contact occurs during the cooling phase (power switched off), the stress in the wire decreases with respect to the nominal value because part of the load exerted by the dead load or the spring is partly sustained by the hard stop. No adjustment on the supply current is made to avoid this stress decrease because these test conditions are typical of what actually happens in real-world actuators where the limit positions of the output port are mostly determined by hard-stops.

\section{Tests under "Constant-stress" and "Constant-stress with limited max strain"}

For the tests in constant-stress (both free and with limited maximum strain) the wire coupons were cut from the coil and electrical-type cord end ferrules (http://www.partex.co.uk/cefs.html) were crimped to both ends giving a net test length of $100 \mathrm{~mm}$. Each wire was loaded by filling the basket with lead beads until the desired stress in the wire (read by the primary load cell) was achieved. The heating of the wire was provided by sinusoidal current oscillating from zero to a peak value capable of producing the full transformation of the alloy under the cooling conditions adopted.

The maximum achievable frequency was limited by the force ripples in the wire produced by the inertia of the moving basket and by full transformation of the alloy $(\mathrm{M} \rightarrow \mathrm{A}, \mathrm{A} \rightarrow \mathrm{M})$. The maximum strain rate measured during the constantstress tests ranged between $0.150 \mathrm{~s}^{-1}$ and $0.300 \mathrm{~s}^{-1}$ during activation and between $0.065 \mathrm{~s}^{-1}$ and $0.150 \mathrm{~s}^{-1}$ during relaxation. The tests were terminated automatically at fracture of the SMA wire (no current flowing in the sample) or when the sample survived a prescribed number of cycles $\left(5 \times 10^{5}\right)$.

The constant-stress tests with limited maximum strain were carried out for two levels of limit strain: $\varepsilon_{\text {lim }}=3 \%, 4 \%$. Further information on the testing procedure is available from [10].

\section{Tests under "Constant-strain"}

The constant-strain tests were performed on wire lengths of $100 \mathrm{~mm}$ cut from the same coil as the constant-stress tests and mounted on the machine using the same end crimping technique. The prescribed strain (read by the position transducer in Fig. 2) was applied to the wire by lowering the restraining cross-head in Fig. 2b. The heating of the wire was provided by sinusoidal current oscillating from zero to a peak value capable of producing the full transformation of the alloy under the cooling conditions adopted. The test was terminated automatically at fracture of the SMA wire (no current flowing in the sample) or when a prescribed number of cycles $\left(5 \times 10^{5}\right)$ was endured with no failure. The experimental plan adopted in the test campaign included five strain values $(1,2,3,4$ and $5 \%)$ with three samples per level. More details on the testing procedure are available from [10].

\section{Tests under "Linear stress-strain variation"}

Using the set-up in Fig. 2d, the tests under linear stress-strain variations were carried out by choosing the following three characteristic parameters for each test: the stress-strain slope (controlled by the stiffness of the backup spring), the limit maximum strain (3\% and $4 \%$ were the selected values) and the pre-stress in the wire before start (controlled by the spring preload). The stress-strain slope and the limit maximum strain remained constant for an entire test run, with each run involving a set of single tests performed for different pre-stresses. The pre-stress in the wire was used as control variable much in the same way as the stress level in the constant-stress tests or the strain level in the constant-strain tests described above. This is not the only way to perform the tests under linear stress-strain variations but it is by far the simplest choice from an experimental point of view and the most realistic from a practical standpoint. Experimentally, this procedure allowed the entire set of results for given maximum strain and given stress-strain slope (single backup spring) to be easily collected and readily elaborated with standard statistical methods (see Results and Discussion). In practical terms, this procedure fits well with the normal stress-strain conditions occurring in real-life actuators where a given backup spring with a particular spring rate fixes the stress-strain slope in the active SMA element for its entire life.

The tests performed so far derive from a single backup spring (with spring rate $k_{b}=0.62 \mathrm{~N} / \mathrm{mm}$ ) and a limit maximum strain $\varepsilon_{\text {lim }}=4 \%$. The pre-stress levels were chosen so as to coincide with the stress levels of the constant-stress tests with the maximum strain (Section Tests under "Constant-stress" and "Constant-stress with limited max strain") limited to the same value 
$\varepsilon_{\text {lim }}=4 \%$. Starting from the maximum applied stress in the first test, the stress level was lowered stepwise in the next tests until no fracture in the wire was observed after a life of $5 \times 10^{5}$ cycles. After accomplishment of the first runout, the staircase method was performed according to the method described in [10].

Also in this test, the heating of the wire was provided by a sinusoidal current oscillating from zero to a peak value capable of producing the full transformation of the alloy under the cooling conditions adopted.

\section{RESULTS AND DISCUSSION}

he data of applied stress $(\sigma)$ and cycles to failure $\left(N_{f}\right)$ obtained from the test campaign under constant stress (circles) and constant stress with limited maximum strain (triangles and diamonds for limit strains of 3\% and 4\%, respectively) are plotted in the semi-log Woehler diagram of Fig. 3 together with the bilinear interpolation (solid line for constant stress, dotted and dashed lines for limit strains of $3 \%$ and $4 \%$, respectively). The interpolations were obtained through statistical treatment of the results according to the accelerated staircase method [11] developed by the Japanese Society of Mechanical Engineers (JSME). Fig. 3 shows that the inclined part of the Woehler's curves is well represented by straight lines. The slope of the interpolating line is $\sigma / \log \left(N_{f}\right)=101 \mathrm{MPa}$ for the constant-stress test and higher for the constant-stress test with limited maximum strain, which have a common slope $\sigma / \log \left(N_{f}\right)=245 \mathrm{MPa}$, regardless of the specific strain limit. These results show that putting a limit, however small, to the maximum strain during constant-stress tests is extremely beneficial to the fatigue life. It is worth noting that limiting the maximum strain to $3 \%$ does not produce further advantages because the sloped legs of the Woehler's curves in Fig. 3 for 3\% (dashed line) and $4 \%$ maximum strain (dotted line) are very close to each other. This occurrence suggests that a threshold limit strain does exist above which the described life increase is definitely obtained with respect to constant-stress tests with unlimited strain.

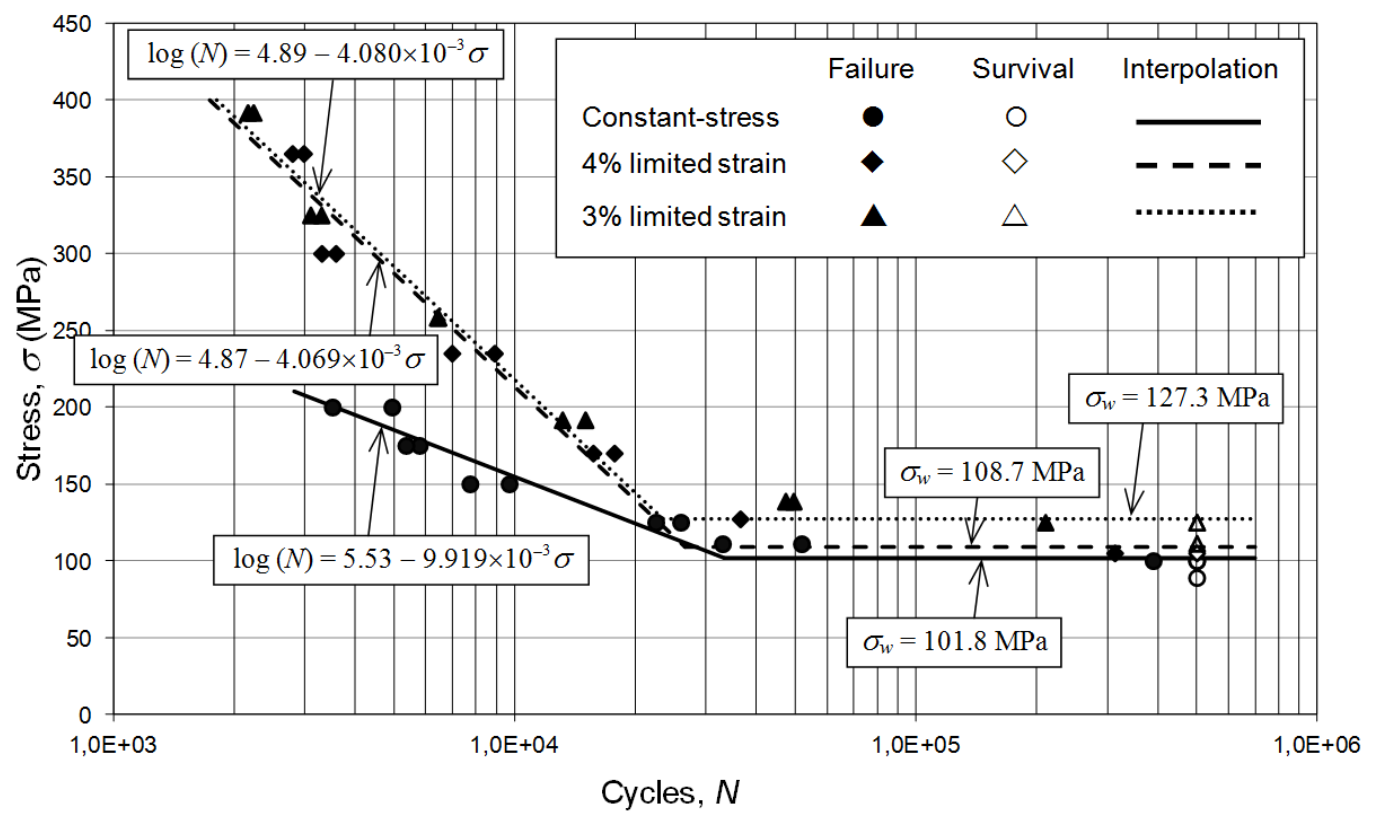

Figure 3: Woehler's diagram with the fatigue results for the constant-stress tests and the tests at constant stress with limited maximum strain $(3 \%$ and $4 \%)$.

The distribution of the experimental points in Fig. 3 along the horizontal part of the Woehler's curve suggests the existence of a true fatigue limit of the material under constant-stress conditions, both for limited and unlimited maximum strains. This conclusion is supported by the fact that a sample wire which had survived the staircase method (5x105 cycles) was mounted on the machine and cycled again up to one million cycles without any sign of failure.

The fatigue limit for the constant-stress tests calculated from Fig. 3 for the chosen life $\left(5 \times 10^{5}\right.$ cycles $)$ is $\sigma_{w}=101.8 \mathrm{MPa}$. For constant-stress tests with limited maximum strain the fatigue limits estimated by the JSME elaboration is greater here than for the constant-stress conditions and takes up for decreasing limit strain (108.7 and $127.3 \mathrm{MPa}$ for limit strains of $4 \%$ and 
$3 \%$, respectively). All these fatigue limits are calculated with a confidence level of $50 \%$. Quantitatively, the difference between the fatigue limits with limited strain and the fatigue limit at constant-stress is proportional to the difference in strains achieved in the tests under those stresses.

Fitting the fatigue data for the constant-stress tests with Coffin-Manson equation, we obtain a fatigue ductility exponent $\mathrm{c}=0.4894$. This result is very similar to that obtained by Laogoudas $(0.47 \div 0.49)$ in [5] for an NiTiCu alloy.

The strength-life (Woehler's) curve in Fig. 4 (semi-log diagram) for the constant-strain tests features only the inclined part (the wire failed for all strain levels tested between 1\% and 5\%) and there is no indication of a strain threshold (strain fatigue limit). The slope of the interpolating line is $\varepsilon / \log \left(N_{f}\right)=8.28$ ( $\varepsilon$ expressed in percent). The functional life can be as low as 7000 cycles (for applied strain of 5\%) and never exceeds 19000 cycles (applied strain of 1\%) in the strain range investigated. This outcome confirms that the constant-strain loading condition is much more demanding on the material than the constant-stress test, even though the maximum strains induced in the alloy are of the same order of magnitude in the two tests. Fig. 5 shows that the stress induced in the wire during constant-strain cycles decreases exponentially with the number of cycles. The residual stress just before failure falls in the range 400-500 MPa, regardless of the strain applied. Dropping of the maximum stress into this range could be adopted as a predictor of incipient fracture of the material undergoing constant-strain functional cycling of whatever amplitude.

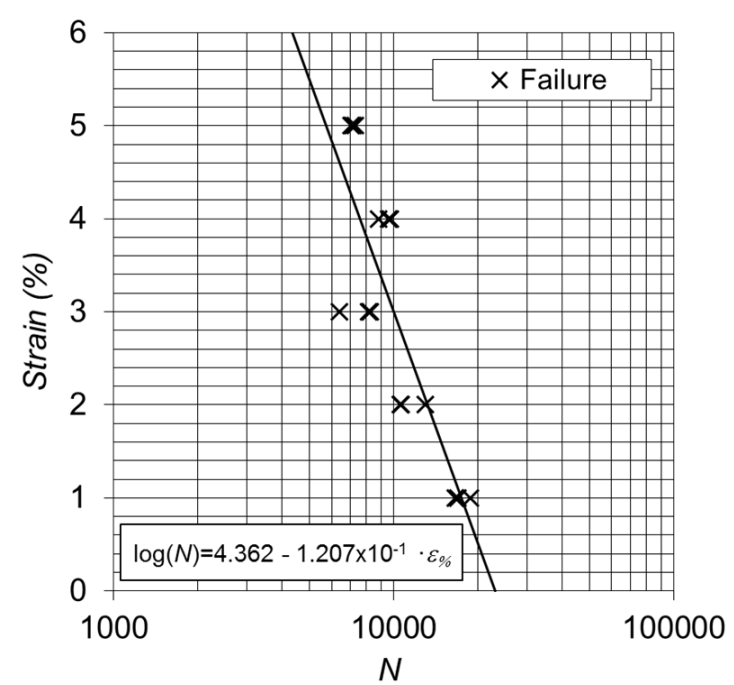

Figure 4: Woehler's diagram with the fatigue results for the constant-strain tests.

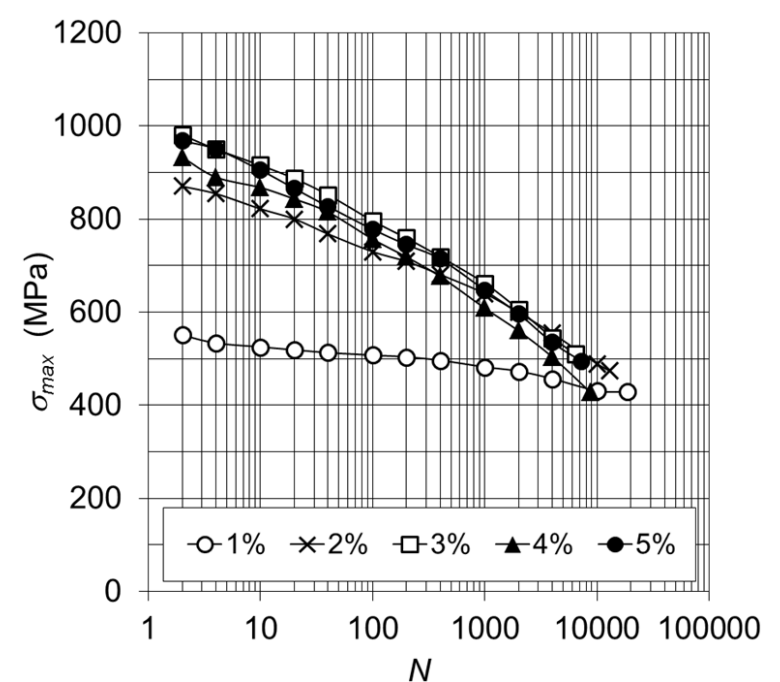

Figure 5: Evolution of the maximum stress in the wire under constant-strain loading.

Tab. 1 compares the preliminary results obtained from the tests under linear stress-strain variation (lines 1, 3, 5, 7, 9, 11, 13, and 15) with the results for the constant-stress test with limited strain (lines 2, 4, 6, 8, 10,12, 14, and 16). For each line, Tab. 1 reports the number of cycles to failure, $\mathrm{Nf}$, and, separately for the second cycle after start and for the last cycle before termination, the maximum stress achieved, $\sigma_{\max }$, together with the actual minimum $\left(\varepsilon_{\min } \equiv \varepsilon_{A}\right)$, maximum $\left(\varepsilon_{\max } \equiv \varepsilon_{M}\right)$ and differential (SME $\left.\equiv \Delta \varepsilon=\varepsilon_{\max }-\varepsilon_{\min }\right)$ strains measured in the wire. From Tab. 1 it is seen that the reference life of $5 \times 10^{5}$ cycles is achieved only for test 15 under a stress of $82.8 \mathrm{MPa}$. For the highest stress levels $(300,235$ and $170 \mathrm{MPa})$ the number of cycles to failure is almost the same for both test conditions.

The stress-life data from Tab. 1 are plotted in Fig. 6 as Woehler's curves. The dashed line is the same as in Fig. 3 for the constant-stress test with maximum strain limited to $4 \%$, while the solid line represents the linear interpolation of the data available so far for the linear stress-strain variation. The inclined legs of both Woehler's curves are nearly perfectly superimposed, suggesting that the linear stress-strain variation does not change the fatigue life, for the particular stiffness of the backup spring adopted, with respect to the test under purely constant stress. This behaviour is similar to what was observed from Fig. 3 in relation to the negligible effect of the limit strain for the constant-stress tests with limited maximum strain. The ongoing tests will show whether the fatigue limit for the linear stress-strain variation will be different from the constant-stress test for the same limit strain of $4 \%$. 


\begin{tabular}{|c|c|c|c|c|c|c|c|c|c|c|c|c|}
\hline & \multirow[b]{3}{*}{ Test } & \multirow[b]{3}{*}{$\begin{array}{l}\varepsilon_{\text {lim }} \\
(\%)\end{array}$} & \multirow[b]{3}{*}{$\begin{array}{c}\sigma, \sigma_{p} \\
(\mathrm{MPa})\end{array}$} & \multirow[b]{3}{*}{$N_{f}$} & \multirow{2}{*}{\multicolumn{4}{|c|}{ Second gycle after start }} & \multirow{2}{*}{\multicolumn{4}{|c|}{ Last cycle before termination }} \\
\hline \multirow[b]{2}{*}{ Line } & & & & & & & & & & & & \\
\hline & & & & & $\begin{array}{c}\sigma_{\max } \\
(\mathrm{MPa})\end{array}$ & $\begin{array}{c}\varepsilon_{\min } \equiv \mathcal{E}_{A} \\
(\%)\end{array}$ & $\begin{array}{c}\varepsilon_{\max } \equiv \varepsilon_{M} \\
(\%)\end{array}$ & $\begin{array}{c}\Delta \varepsilon \equiv S M E \\
(\%)\end{array}$ & $\begin{array}{c}\sigma_{\max } \\
(\mathrm{MPa})\end{array}$ & $\begin{array}{c}\varepsilon_{\min } \equiv \varepsilon_{A} \\
(\%)\end{array}$ & $\begin{array}{c}\varepsilon_{\max } \equiv \varepsilon_{M} \\
(\%)\end{array}$ & $\begin{array}{c}\Delta \varepsilon \equiv S M E \\
(\%)\end{array}$ \\
\hline 1 & Linear stress-strain & 4.0 & 300 & 4728 & 425 & 0.96 & 4.03 & 2.27 & 370 & 2.62 & 3.97 & 1.35 \\
\hline 2 & Constant-stress & 4.0 & 300 & 3579 & 311 & 0.57 & 4.099 & 23.03 & 310 & 2.08 & 4.08 & 2.00 \\
\hline 3 & Linear stress-strain & 4.0 & 300 & 4597 & 416 & 0.97 & 3.91 & 2.54 & 359 & 2.53 & 3.93 & 1.40 \\
\hline 4 & Constant-stress & 4.0 & 300 & 3301 & 311 & 0.53 & 4.048 & 23.07 & 312 & 1.99 & 4.05 & 1.26 \\
\hline 5 & Linear stress-strain & 4.0 & 235 & 8193 & 367 & 0.76 & 4.03 & 2.47 & 328 & 1.86 & 4.02 & 1.36 \\
\hline 6 & Constant-stress & 4.0 & 235 & 8899 & 241 & 0.35 & 4.00 & 3.25 & 243 & 1.15 & 4.00 & 2.45 \\
\hline 7 & Linear stress-strain & 4.0 & 235 & 8000 & 380 & 0.80 & 4.00 & 2.40 & 339 & 1.91 & 3.99 & 2.08 \\
\hline 8 & Constant-stress & 4.0 & 235 & 6972 & 242 & 0.39 & 4.03 & 3.24 & 243 & 1.24 & 4.05 & 2.41 \\
\hline 9 & Linear stress-strain & 4.0 & 170 & 18723 & 293 & 0.60 & 4.00 & 3.00 & 267 & 1.30 & 3.88 & 2.58 \\
\hline 10 & Constant-stress & 4.0 & 170 & 17693 & 188 & 0.35 & 4.00 & 3.25 & 174 & 0.81 & 4.00 & 2.39 \\
\hline 11 & Linear stress-strain & 4.0 & 170 & 14673 & 320 & 0.61 & 4.03 & 3.02 & 288 & 1.42 & 4.02 & 2.20 \\
\hline 12 & Constant-stress & 4.0 & 170 & 15665 & 178 & 0.28 & 4.036 & 23.32 & 177 & 0.80 & 4.04 & 2.44 \\
\hline 13 & Linear stress-strain & 4.0 & 105 & 21678 & 248 & 0.50 & 4.00 & 3.10 & 228 & 0.94 & 3.98 & 3.04 \\
\hline 14 & Constant-stress & 4.0 & 105 & 500000 & 110 & 0.22 & 4.00 & 3.38 & 109 & 0.70 & 4.00 & 2.50 \\
\hline 15 & Linear stress-strain & 4.0 & 82.8 & 500000 & 221 & 0.42 & 3.96 & 3.54 & 196 & 1.08 & 3.95 & 3.27 \\
\hline 16 & Constant-stress & 4.0 & 82.8 & 500000 & 85 & 0.08 & 3.95 & 4.27 & 85 & 0.39 & 3.97 & 3.58 \\
\hline
\end{tabular}

Table 1: Comparison of fatigue results between the tests under linear stress-strain variation (39 MPa for each percent of strain) with maximum strain limited to $4 \%$ and the constant-stress tests with limited maximum strain of $4 \%$.

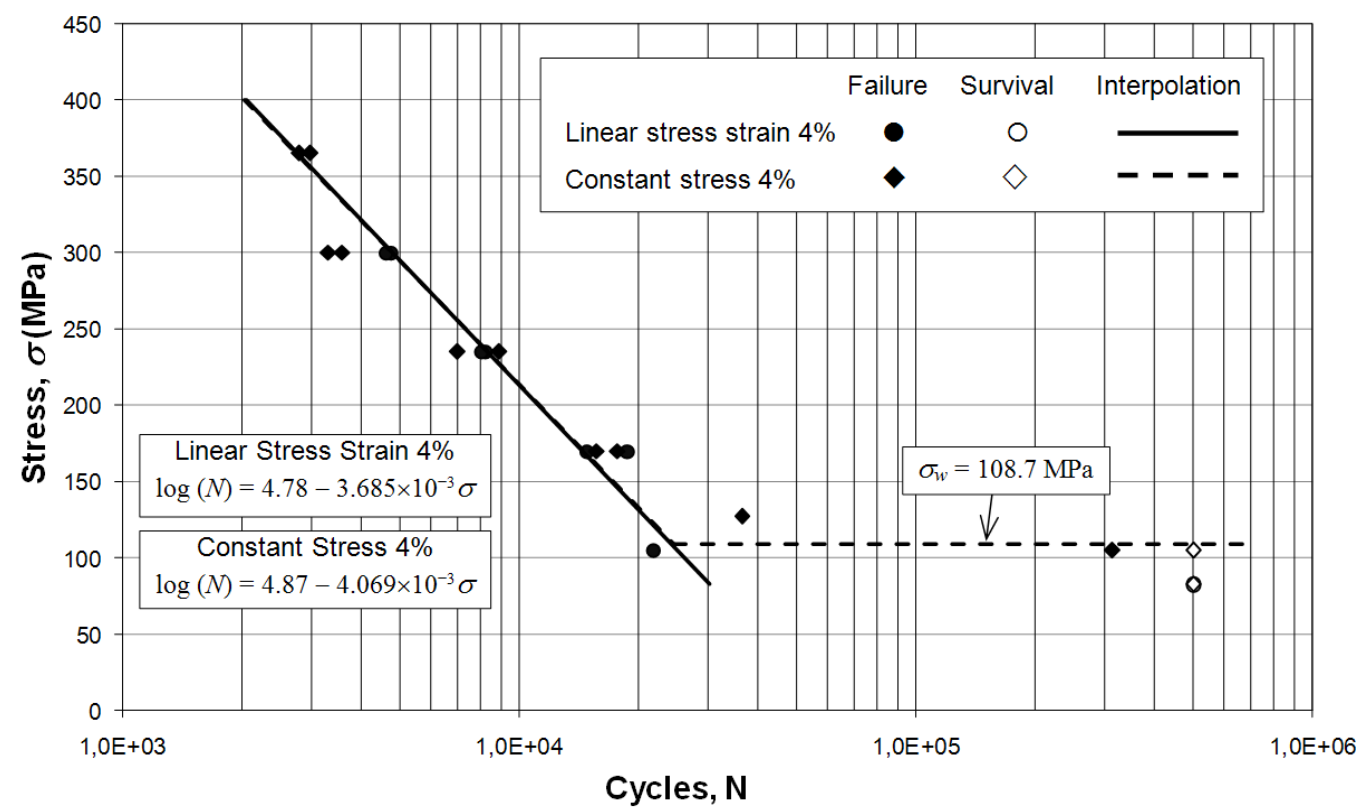

Figure 6: Woehler's diagram with the fatigue results for the tests under linear stress-strain variation and maximum strain of $4 \%$. Woehler's curve for the constant stress tests with maximum strain limited to $4 \%$ is shown for comparison (dashed line). 


\section{CONCLUSIONS}

his paper proposes four types of tests to characterize shape memory wires under functional fatigue loading: constant-stress test, constant-strain test, constant-stress test with limited maximum strain, linear stress-strain variation with limited maximum strain. Tests carried out on commercial NiTi wires (0.15 mm SAES Getters Smartflex $\left.{ }^{\circledR}\right)$ under all four loading conditions have produced interesting results. For the conditions of "Constant-stress" and "Constant-stress with limited max strain" the stress-life curve on a semi-log diagram is similar to the ordinary metals, with an initial inclined line followed by a final horizontal line that identifies a fatigue limit (at $5 \times 10^{5}$ cycles). In the "Constant-stress with limited max strain test", the increase of the fatigue limit with respect to the regular constant-stress test is proportional to the difference between the maximum strains. Exposure to constant-strain conditions due to overrestraint of the wire promoted by dynamic loading is very detrimental to the fatigue life and should be avoided. Preliminary tests under linear stress-strain variation (39 MPa for each percent strain) with limited maximum strain (4\%) show a marked reduction of the fatigue limit with respect to constant-stress tests with the same limit maximum strain. Interestingly, although the data available so far suggest that the fatigue limit is higher for the constant-stress test, the slope of the inclined part of Woehler's curve is almost the same for both test conditions.

\section{REFERENCES}

[1] Spinella, E. Dragoni, Proc Instn Mech Engrs, Part C: J. of Mechanical Engineering Science, 223 (2009) 531.

[2] G. Eggeler, E. Hornbogen, A. Yawny, A. Heckmann, M. Wagner, Materials Science and Engineering A, 378 (2004) 24.

[3] L. Fumagalli, F. Butera, A. Coda, J. of Materials Engineering and Performance, 18 (2009) 691.

[4] M. Mertmann, G. Vergani, Eur. Phys. J. Special Topics, 158 (2008) 221.

[5] D. C. Lagoudas, D. A. Miller, L. Rong, P. K. Kumar, Smart Materials and Structures, 18 (2009) 085021.

[6] M. Mertmann, A. Bracke, E. Hornbogen, J. de physique, IV C8 (1995) 1259.

[7] V. Demers, V. Brailovski, S. D. Prokoshkinb, K. E. Inaekyana, Materials Science and Engineering A, 513-514 (2009) 185.

[8] G. Scirè Mammano, E. Dragoni, Engineering Procedia, 10 (2011) 3962.

[9] S. J. Furst, J. H. Crews, S. Seelecke, Continuum Mechanics and Thermodynamics, 24 (2012) 485.

[10] G. Scirè Mammano, E. Dragoni, Functional fatigue of Ni-Ti shape memory wires under various loading conditions. Int. J. fatigue 2012 (In press) http:/ / dx.doi.org/10.1016/j.ijfatigue.2012.03.004

[11] H. Nakazawa, S. Kodama, Statistical research on fatigue and fracture, (1987) 59.

\section{APPENDIX 1}

\section{Nomenclature}

$A_{f} \quad$ Austenite finish temperature

$A_{s} \quad$ Austenite start temperature

$c \quad$ Empirical constants in Coffin-Manson equation

$k_{b} \quad$ Spring rate of the backup spring in the test with linear stress-strain variation

$M_{f} \quad$ Martensite finish temperature

$M_{s} \quad$ Martensite start temperature

$N_{f} \quad$ Number of cycles to failure

SME Shape memory effect $\left(\equiv \Delta \varepsilon=\varepsilon_{M}-\varepsilon_{A}\right)$

$S_{0} \quad$ Initial stress level in the JSME fatigue test method

$\varepsilon \quad$ Wire strain

$\varepsilon_{a} \quad$ Amplitude of total strain cycle

$\varepsilon_{A} \quad$ Wire strain in the austenitic state

$\varepsilon_{\text {lim }} \quad$ Maximum wire strain in the constant-stress test and in linear stress-strain cycle with limited maximum strain

$\varepsilon_{M} \quad$ Wire strain in the martensitic state 
$\varepsilon_{\max } \quad$ Maximum wire strain recorded in the cycle $\left(\equiv \varepsilon_{M}\right)$

$\varepsilon_{\min } \quad$ Minimum wire strain recorded in the cycle $\left(\equiv \varepsilon_{A}\right)$

$\Delta \varepsilon \quad$ Shape memory effect $\left(\equiv S M E=\varepsilon_{M}-\varepsilon_{A}\right)$

$\sigma \quad$ Nominal stress applied to the wire

$\sigma_{\max } \quad$ Maximum wire stress recorded in the cycle

$\sigma_{p} \quad$ Pre-stress in the wire under the maximum strain in the linear stress-strain cycle

$\sigma_{w} \quad$ Fatigue limit 